\title{
Medicinal Plants for the Treatment of Hypertrophic Scars
}

\author{
Qi Ye, ${ }^{1,2}$ Su-Juan Wang, ${ }^{3}$ Jian-Yu Chen,, ${ }^{2,4}$ Khalid Rahman, ${ }^{5}$ \\ Hai-Liang Xin, ${ }^{6}$ and Hong Zhang ${ }^{2,3}$ \\ ${ }^{1}$ College of Life Science, Fujian Agriculture and Forestry University, Fuzhou 350002, China \\ ${ }^{2}$ Department of Pharmaceutical Botany, School of Pharmacy, Second Military Medical University, Shanghai 200433, China \\ ${ }^{3}$ Central Laboratory, Shanghai Seventh People's Hospital, Shanghai 200137, China \\ ${ }^{4}$ State Key Laboratory of Quality Research in Chinese Medicine, Macau Institute for Applied Research in Medicine and Health, \\ Macau University of Science and Technology, Macau \\ ${ }^{5}$ School of Pharmacy and Biomolecular Sciences, Faculty of Science, Liverpool John Moores University, Liverpool L3 3AF, UK \\ ${ }^{6}$ Department of Pharmacognosy, School of Pharmacy, Second Military Medical University, Shanghai 200433, China
}

Correspondence should be addressed to Hong Zhang; huihong01@126.com

Received 28 September 2014; Revised 24 January 2015; Accepted 8 February 2015

Academic Editor: Avni Sali

Copyright (C) 2015 Qi Ye et al. This is an open access article distributed under the Creative Commons Attribution License, which permits unrestricted use, distribution, and reproduction in any medium, provided the original work is properly cited.

\begin{abstract}
Hypertrophic scar is a complication of wound healing and has a high recurrence rate which can lead to significant abnormity in aesthetics and functions. To date, no ideal treatment method has been established. Meanwhile, the underlying mechanism of hypertrophic scarring has not been clearly defined. Although a large amount of scientific research has been reported on the use of medicinal plants as a natural source of treatment for hypertrophic scarring, it is currently scattered across a wide range of publications. Therefore, a systematic summary and knowledge for future prospects are necessary to facilitate further medicinal plant research for their potential use as antihypertrophic scar agents. A bibliographic investigation was accomplished by focusing on medicinal plants which have been scientifically tested in vitro and/or in vivo and proved as potential agents for the treatment of hypertrophic scars. Although the chemical components and mechanisms of action of medicinal plants with antihypertrophic scarring potential have been investigated, many others remain unknown. More investigations and clinical trials are necessary to make use of these medical plants reasonably and phytotherapy is a promising therapeutic approach against hypertrophic scars.
\end{abstract}

\section{Introduction}

Scar formation strongly depends on the presence of contraction during healing and the nature of the scar is actually the uneven look of the healed tissue resulting from disfigured tissue deformation and overaligned collagen fibers [1]. Collagen in hypertrophic scars is found to be in a disorganized, whorl-like arrangement rather than in the normal parallel orientation manner. Therefore, hypertrophic scars are indurate, elevated, poorly extensible, and also characterized by hypervascularity, thereby providing their erythematous appearances [2]. HS can cause significant abnormality in aesthetic and functional symptoms and to date no recognized treatment has been established. It commonly occurs after surgical incision, thermal injury, and traumatic injuries to the dermis with a subsequent abnormal healing response
[3]. Furthermore, it is often associated with contractures that can lead to considerably reduced functional performance in patients.

The development of antihypertrophic scars is an unsolved problem in the process of scar treatment. For this reason, some undiscovered successful treatments are needed to prevent excessive hypertrophic scarring. The reported preventions include topical medical application, cryotherapy, use of silicone gel sheets, injection of steroids, radiotherapy, and an early surgical procedure for wound closure [2]. In the last decade, there has been a renewed interest in the use of indigenous medicine worldwide, arising from the realization that orthodox medicine is not widespread. Although modern medicine may be available in some communities, herbal medicines have often maintained popularity for historical and cultural reasons, in addition to their cheaper costs [4]. 


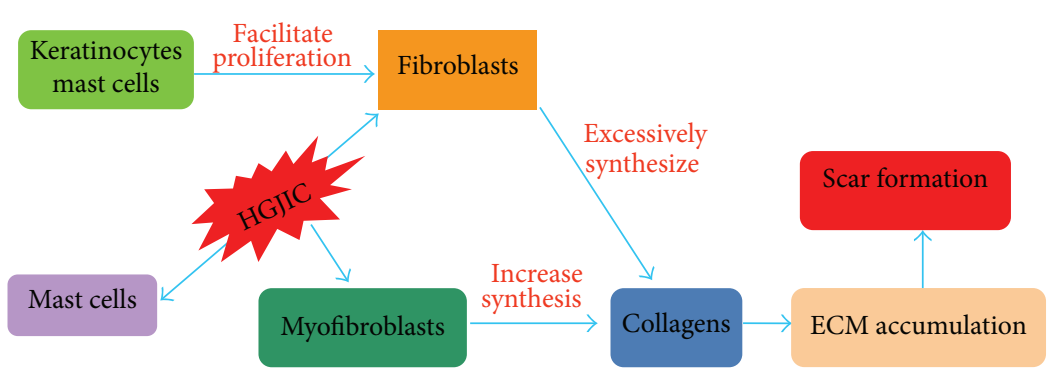

FIGURE 1: The mechanism of hypertrophic scarring.

Recent research has introduced the uses of phytochemical compounds and extracts isolated from medicinal plants in an attempt to resolve these problems as a promising therapy.

Many treatment strategies are sought to prevent scar formation without compromising the wound healing process [5]. The effectiveness of currently used therapy against hypertrophic scar arises most probably from the increase of the medicinal plants reported. In the modern system of medicine, about $25 \%$ of prescriptions contain active principle(s) derived from plants [4]. A significant correlation between medicinal plants and their use in the treatment of many types of scars has been shown in epidemiological data generated throughout the world. Published clinical trials have, as yet, largely focused on characterizing the pharmacokinetics and metabolism of medicinal plants. Despite experimental advances in medicinal plant research against scars, findings in humans are still limited. However, in recent years, diverse benefits of medicinal plants in the treatment of hypertrophic scars have been described [6-9].

In line with the latest findings responsible for the increased recognition of medicinal plants as potential therapeutic and/or preventative agents, the aim of the present review is to focus on recent experimental findings and clinical trials of medicinal plants and other preparations with similar actions that could account for beneficial effects on hypertrophic scars in patients. Natural products, such as plant extracts, either as pure compounds or as standardized extracts, provide unlimited opportunities for control of hypertrophic scarring owing to their chemical diversity [10]. Currently, a great deal of effort is being expended to find alternative sources of safe, effective, and acceptable natural medicinal plants for the treatment or prevention of hypertrophic scars; hence, all literature available was reviewed.

\section{Suggested Mechanism of Hypertrophic Scarring}

The molecular mechanism of hypertrophic scarring is associated with the unusual proliferation of fibroblasts and overproduction of collagen and extracellular matrix [70]. An array of intra- and extracellular mechanisms is essential in the prevention of scar formation. With the help of molecular biology, cell biology technology, hypertrophic scar animal models, and the setting-up of scar tissue engineering, the mechanism of hypertrophic scarring has been clearly defined (Figure 1). It is usually considered as migration and proliferation of different cell types such as keratinocytes, myofibroblasts [59], and mast cells [71]. Fibroblasts play an essential role in new tissue formation during wound repair [33], but their abnormal low death rate and high proliferation rate can cause scar tissue formulation [11]. Meanwhile, keratinocytes are indispensable in signal transduction between paracrine secretion and epithelium matrix. When cultured in the presence of keratinocytes, fibroblasts exhibit significant proliferation activity [72], showing the contribution of keratinocytes to fibroblasts proliferation. Myofibroblasts, which are different from fibroblasts and are related to the composition, organization, and mechanical properties of ECM [73], increase collagen synthesis and retard cell migration [71], thus resulting in excessive and rigid scarring. Fibroblasts are transformed into myofibroblasts by heterocellular gap junction intercellular communications between mast cells (RMC-1) and fibroblasts $[71,74]$. In the process of wound healing, the combination of fibroblasts and myofibroblasts triggers excessive production of abnormal extracellular matrix protein [75], eliciting scarring $[1,75]$. With the assistance of keratinocytes and mast cells, proliferative fibroblasts produce massive collagen which makes extracellular matrix accumulate below dermis, leading to scar formation. The complex forming process consists of three different phases, inflammation, proliferation, and maturation, which leads to hypertrophic scarring in the end [76]. The ratio of I to III collagens in healthy adults ranges from 3.5 to 6.1, while in patients with hypertrophic scars, it could be down to 2 and in keloid patients it can be as high as 19, which is related to the abnormal metabolism of collagens I and III in pathological scars, including more collagen synthesis and less collagen degradation.

Although many targets of action, by which scarring can be inhibited, have been experimentally studied or postulated, few are well known or defined for inhibition of hypertrophic scarring by plant-derived compounds. Figure 2 and Tables 5 and 6 summarize and enumerate the suggested mechanisms and correlative medicinal plants.

The size of a scar is influenced by many factors, such as wound size, wound contraction, and healing time. Wound contraction makes an important contribution to scar formation also the larger the area of the wound, the more cells migrate, resulting in more prominent scarring [1]. Therefore, induction of fibroblast apoptosis and reduction of extracellular matrix and collagen I/III production may be the pivotal measures against hypertrophic scarring. 


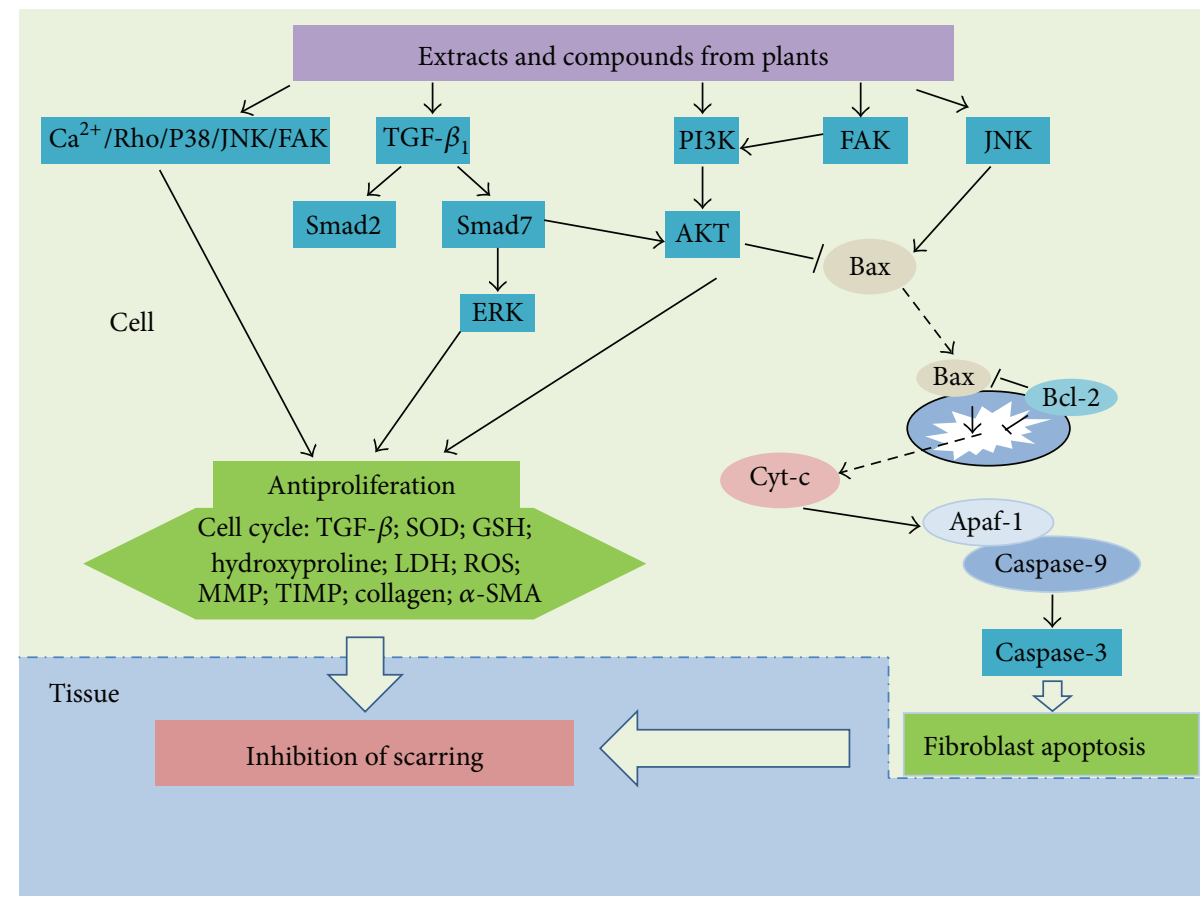

FIGURE 2: The mechanisms by which extracts and compounds from medicinal plants display antihypertrophic scar activity.

Many kinds of test models are applied to investigate wound healing mechanisms and inhibition of scar formation, including 2D hybrid agent-based model [1], pig surgical injury model, fibroblast populated collagen lattice (FPCL) model, rat laminectomies at Lumbar-1 level [5], incisional wound healing model [6], and rabbit ear model [54]. These models provide a mean for detecting and evaluating the mechanobiology in wound healing and scar formation [1].

However, the complex mechanism of hypertrophic scarring still remains unknown which raises the question of how to control scar hyperplasia.

\section{Medicinal Plants against Hypertrophic Scarring}

Many beneficial uses of medicinal plants are extensively documented in the traditional medicine systems in many cultures. To collect the data which supports this finding, we performed a systematic review using PubMed, Elsevier, Springer, and Google Scholar databases and peer-reviewed articles published in the last 10 years. The search terms included scar, scaring, fibroblast, extract, and preparation. The phytochemicals from medicinal plants against scar hyperplasia are presented in Tables 1 and 2, respectively, whilst the medicinal plant extracts are listed in Table 3. Their activities and mechanisms for antihypertrophic scarring were also described, respectively, in Tables 1,2 , and 3 . There are five preparations (Table 4) reported on their effects and mechanisms of antihypertrophic scarring, namely, liposome-encapsulated 10-HCPT, oxymatrine-phospholipid complex (OMT-PLC), solid lipid nanoparticle-enriched hydrogel (SLN-gel), Ginsenoside Rg3/poly (1-lactide) (G-Rg3/PLLA), and Centella asiatica extract capsule, which are composed of different medicinal plants and vehicles. Medicinal plants can be used for different therapeutic purposes or as precursors of useful drugs containing different types of phytochemicals.

The use of herbal medicine remedy has been steadily increasing worldwide in recent years, as well as the search for new phytochemicals that could be potentially developed as useful drugs for the treatment of hypertrophic scar and other scar diseases [4]. The antihypertrophic scar activity of medicinal plants results from a variety of components contained in these plants (Tables 1 and 2). Many plant extracts (Table 3) have antihypertrophic scar activity owing to their phytochemical constituents. However, more work is needed to focus on purification and identification of active components and to elucidate the roles that these play in inhibition of scars when used alone or jointly. Moreover, many of them have not been tested for their cytotoxicity to normal cells, which seriously blocks in vivo investigations. Undeniably, no toxic and side effects have been proved for some active components. For example, Genistein, which is easily obtained and commonly used for hypertrophic scar treatment, has strong pharmacological effects, with no obvious toxicity or side effects [13].

\section{New Preparations of Medicinal Plants}

A large number of extracts and compounds of medicinal plants display antiscar activity. Nevertheless, drugs are difficult to get through the stratum corneum due to the natural barrier of skin, which causes lower permeability of drugs. The oral bioavailability of drugs at the permissive dose is very low, owing to their hydrophilicity (low permeability), 


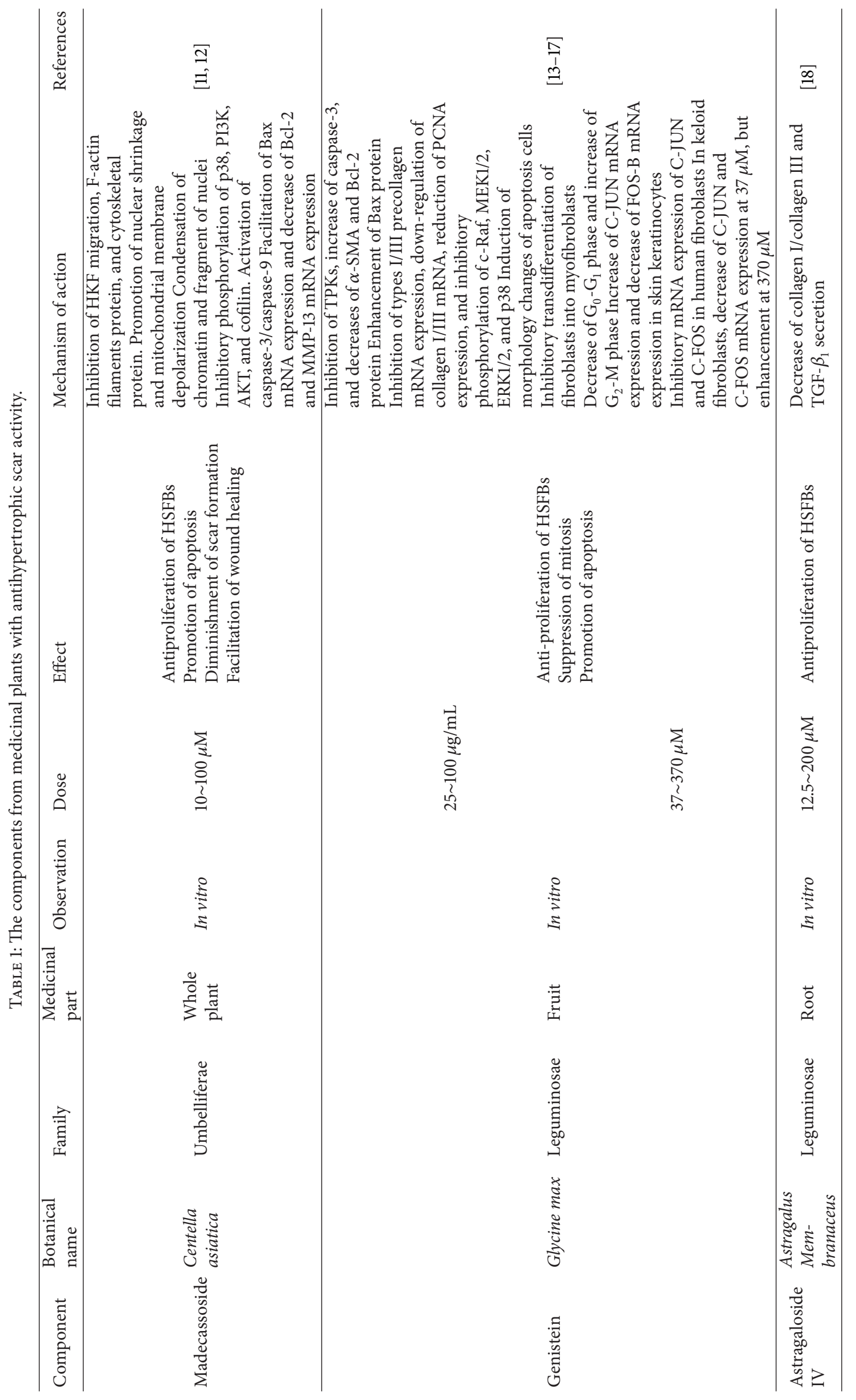




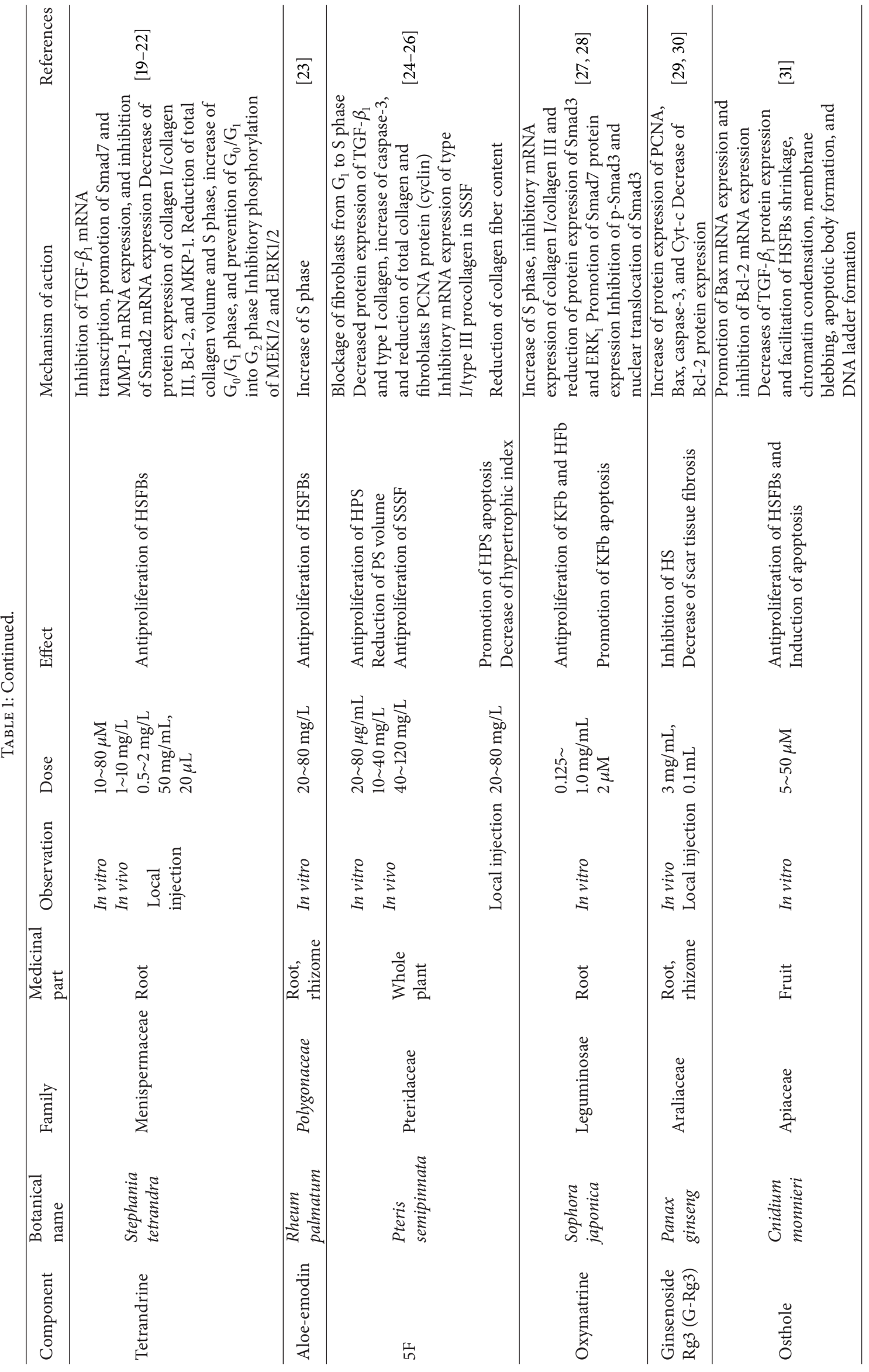




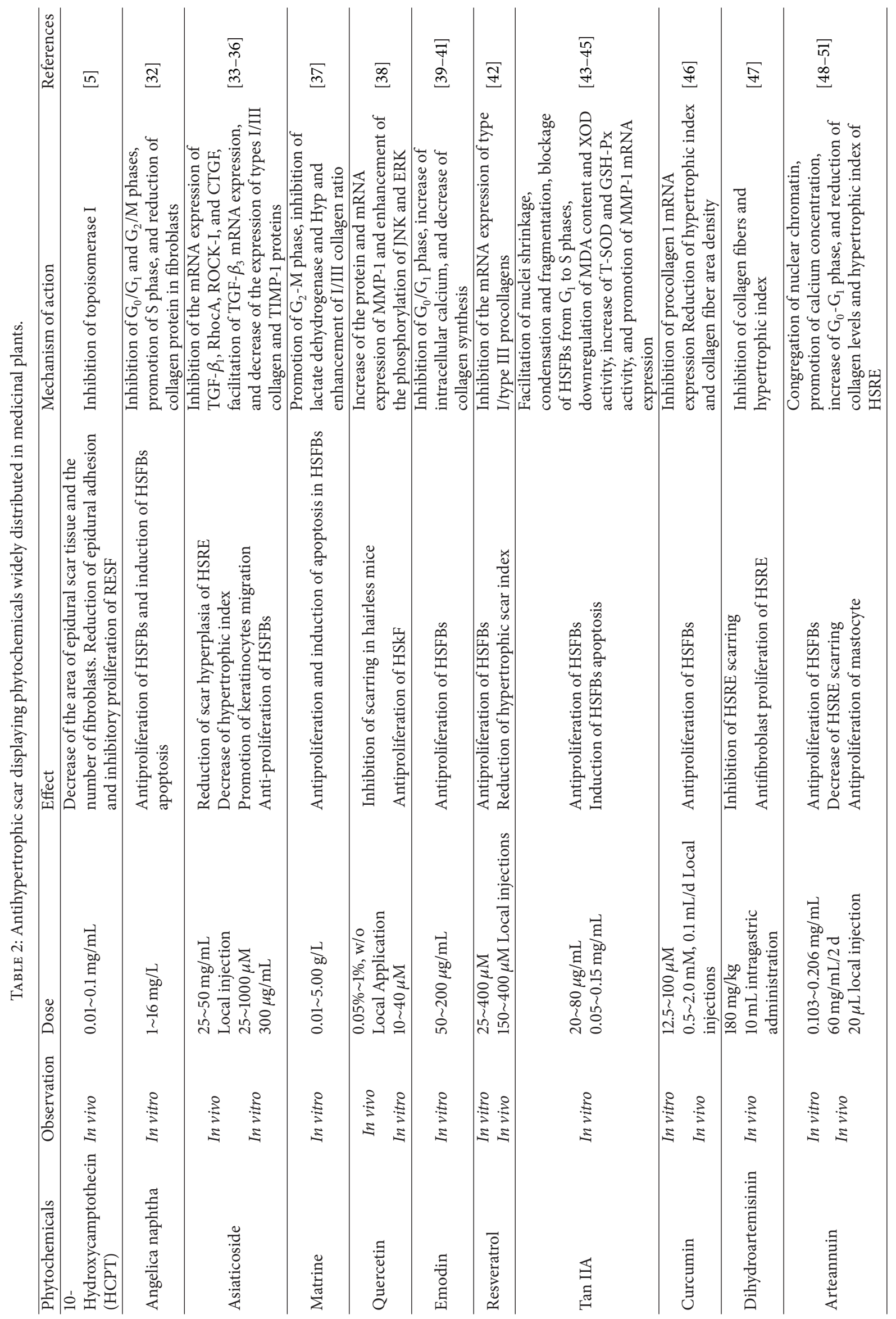




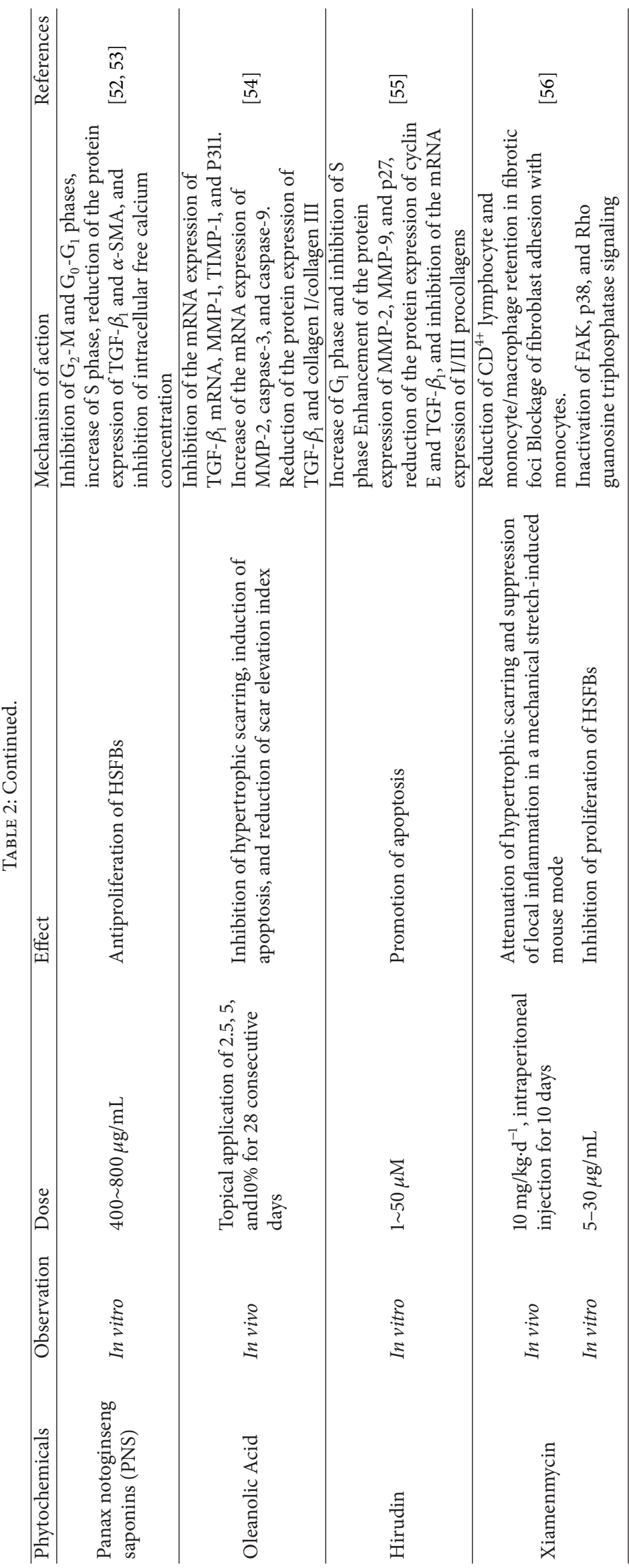




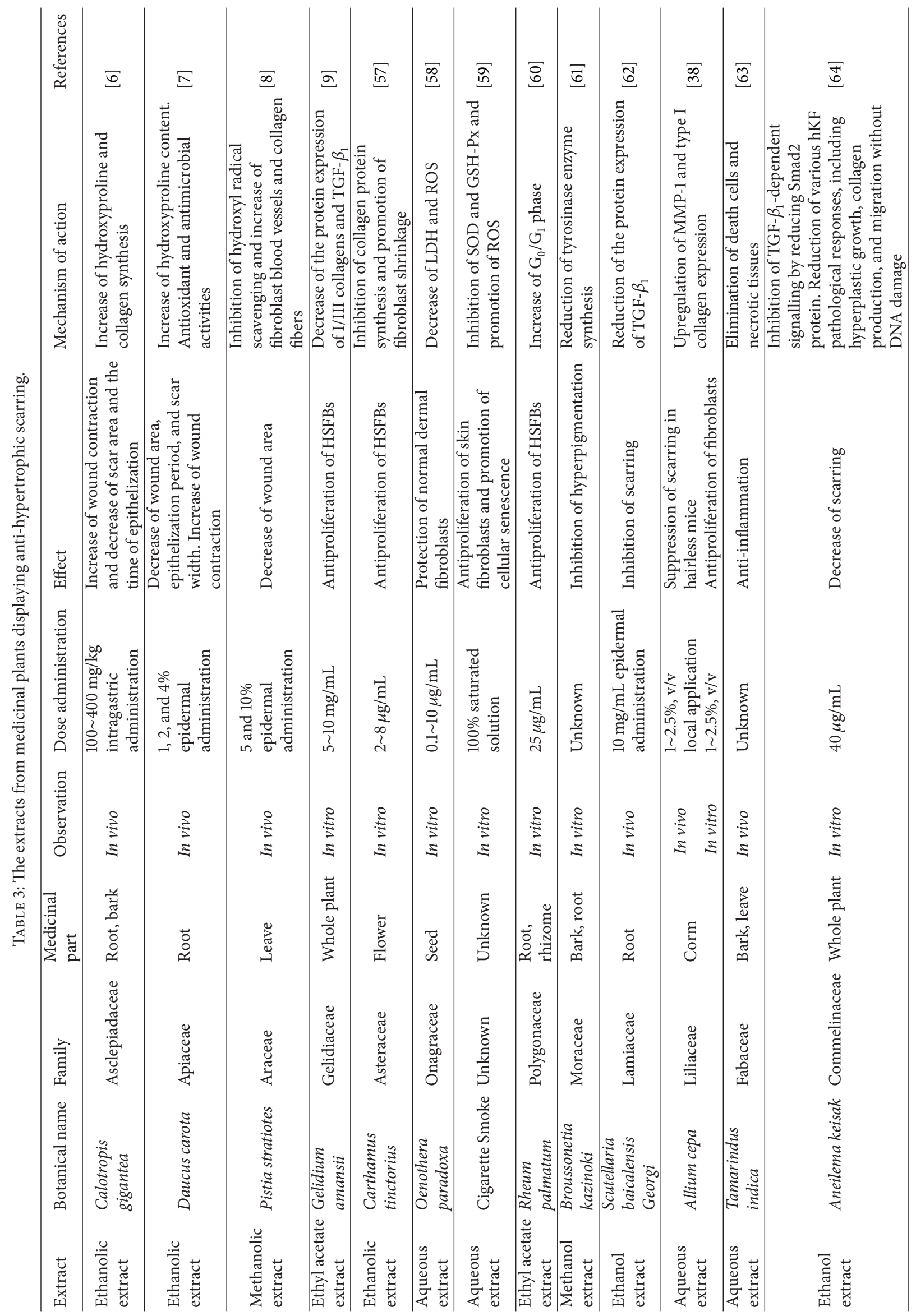




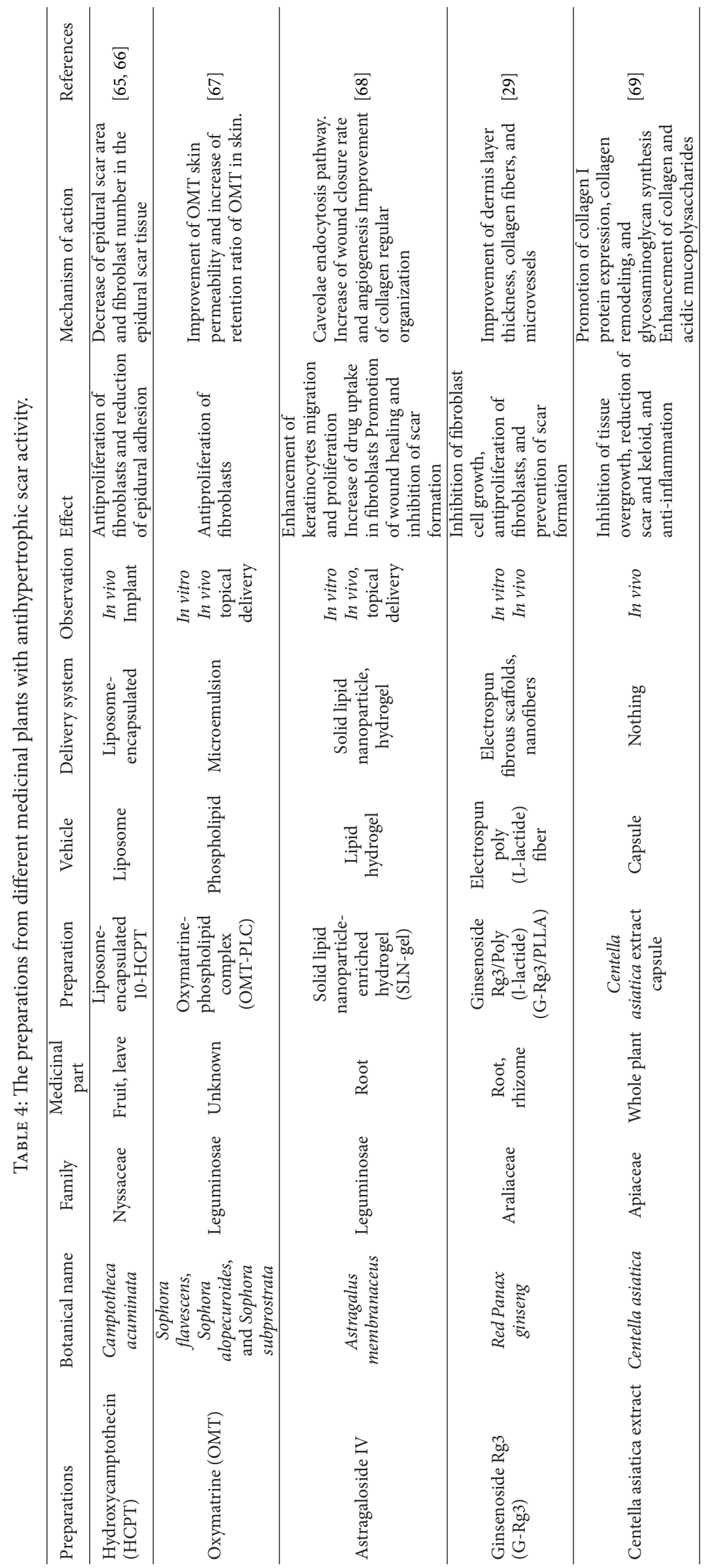


TABLE 5: Summary of antiscarring mechanisms of medicinal plant components.

\begin{tabular}{|c|c|c|}
\hline & Mechanism & Medicinal plant component \\
\hline \multirow{3}{*}{ MAPK pathway } & Inhibition of p-p38 signaling & Madecassoside, Genistein, and Xiamenmycin \\
\hline & Inhibition of p-ERK1/2 signaling & $\begin{array}{l}\text { Genistein, Tetrandrine, Cryptotanshinone, and } \\
\text { Quercetin }\end{array}$ \\
\hline & Inhibition of $\mathrm{p}$-JNK signaling & Quercetin \\
\hline \multicolumn{2}{|l|}{ PI3K/AKT signaling } & Madecassoside \\
\hline \multirow{2}{*}{$\begin{array}{l}\text { Mitochondrial-dependent } \\
\text { pathway }\end{array}$} & Increase of Bax & $\begin{array}{l}\text { Madecassoside, Genistein, Ginsenoside Rg3, and } \\
\text { Osthole }\end{array}$ \\
\hline & Decrease of Bcl-2 & $\begin{array}{l}\text { Madecassoside, Genistein, Tetrandrine, Ginsenoside } \\
\text { Rg3, and Osthole }\end{array}$ \\
\hline \multirow{5}{*}{ Cell cycle } & Increase of cytoplasm Cyt-c & Ginsenoside Rg3 \\
\hline & Decrease of $G_{0}-G_{1}$ phase & $\begin{array}{l}\text { Genistein, Angelica naphtha, Emodin, and Panax } \\
\text { notoginseng saponins }\end{array}$ \\
\hline & Increase of $\mathrm{G}_{2}-\mathrm{M}$ & Genistein \\
\hline & Decrease of S phase & $\begin{array}{l}\text { 10-Hydroxycamptothecin, Tetrandrine, Aloe emodin, } \\
\text { and Hirudin }\end{array}$ \\
\hline & Prevention from $G_{0} / G_{1}$ into $G_{2}$ phase & Tetrandrine \\
\hline RhoA/ROCK-I signal pathway & $\begin{array}{l}\text { Inhibitory secretion of RhocA, ROCK-I, and } \\
\text { CTGF }\end{array}$ & Xiamenmycin \\
\hline VEGF signal pathway & & Cryptotanshinone \\
\hline FAK signal pathway & & Cryptotanshinone, Xiamenmycin \\
\hline TGF- $\beta /$ Smad signaling pathway & & Oxymatrine \\
\hline $\begin{array}{l}\text { Downregulation of collagen I/III } \\
\text { expression }\end{array}$ & & $\begin{array}{l}\text { Genistein, Astragaloside IV, Tetrandrine, Resveratrol, } \\
\text { 5F, Curcumin, Oleanolic Acid, and Hirudin }\end{array}$ \\
\hline Decrease of $\alpha$-SMA & & Genistein, Panax notoginseng saponins \\
\hline \multirow[t]{2}{*}{ Activation of caspases } & Activation of caspase- 3 & $\begin{array}{l}\text { Madecassoside, Genistein, 5F, Cryptotanshinone, } \\
\text { Oleanolic Acid, and Ginsenoside Rg3 }\end{array}$ \\
\hline & Activation of caspase- 9 & Madecassoside, Oleanolic Acid \\
\hline Suppression of TPK activation & & Kazinol F \\
\hline Inhibition of topoisomerase I & & 10-Hydroxycamptothecin \\
\hline Decrease of TGF- $\beta_{1}$ secretion & & $\begin{array}{l}\text { Tetrandrine, Panax notoginseng saponins, Osthole, and } \\
\text { Hirudin }\end{array}$ \\
\hline $\begin{array}{l}\text { Inhibition of TGF- } \beta_{1} \\
\text { transcription }\end{array}$ & & Astragaloside IV, Oleanolic Acid \\
\hline $\begin{array}{l}\text { Downregulation of TIMP-1 } \\
\text { expression }\end{array}$ & & Oleanolic Acid \\
\hline $\begin{array}{l}\text { Reduction of } \mathrm{LDH} \text { and increase } \\
\text { of the ratio of collagen I/collagen } \\
\text { III }\end{array}$ & & Matrine \\
\hline $\begin{array}{l}\text { Increase of T-SOD and GSH-Px } \\
\text { activity }\end{array}$ & & Tan IIA \\
\hline \multirow{3}{*}{ MMP } & Enhancement of MMP-1 & Tetrandrine, Tan IIA, and Oleanolic Acid \\
\hline & Enhancement of MMP-2 and MMP-9 & Hirudin \\
\hline & Enhancement of MMP-13 & Madecassoside \\
\hline Increase of intracellular calcium & & Emodin, Arteannuin \\
\hline
\end{tabular}

poor absorption, and biotransformation or compact scar tissue. The appropriate form of prepared drugs can evidently improve drug permeability, lipid solubility, skin permeability, retention ratio, release time, and cytotoxicity. Hydroxycamptothecin (HCPT) is thought to be one of the most effective components against scars. However, the poor solubility and short half-life severely limit its clinical applications [65].
Compared with HCPT, the liposome-encapsulated HCPT (L-HCPT) can reduce epidural fibrosis by preventing the proliferation of fibroblasts in the scar tissue with longer halflife and better solubility [65]. The application of a silicone derivative to herbal extracts can improve skin pliability and alleviate the concomitant symptoms of scars including pain and itching [2]. However, it is extremely important to control 
TABLE 6: Summary of antiscarring mechanisms of plant extracts.

\begin{tabular}{lc}
\hline Mechanism & Medicinal plants extract \\
\hline Cell cycle & Rhubarb \\
Increase of $\mathrm{G}_{0}-\mathrm{G}_{1}$ phase & Gelidium amansii \\
Collagen & Gelidium amansii, Scutellaria baicalensis Georgi \\
Downregulation of collagen l expression & Calotropis gigantea \\
Downregulation of collagen III expression & Carthamus tinctorius \\
Enhancement of collagen synthesis & Onion \\
Inhibition of collagen synthesis & Neonauclea reticulata, Onion \\
Promotion of collagen I & Neonauclea reticulata \\
MMP & Pistia stratiotes \\
Enhancement of MMP-1 & Oenothera paradoxa \\
Increase of MMP-3 and MMP-9 & Oenothera paradoxa, Neonauclea reticulata \\
Elimination of hydroxyl radical & Cigarette Smoke \\
Decrease of LDH & \\
Decrease of ROS & \\
Increase of ROS and reduction of SOD and GSH-Px &
\end{tabular}

the cytotoxicity of biomaterials for their clinical applications. Microemulsion, a transparent dispersion system, is a good vehicle for drug delivery due to its many advantages such as thermodynamic stability (long shelf life), easy formation (zero interfacial tension), low viscosity, high surface area (high solubilization capacity), and small droplet size [67]. It has been revealed that drug-free microemulsion is a promising preparation due to inapparent cytotoxicity [67]. The local or transdermal application of water-soluble pharmaceutical formulation may be suitable for medicinal plant extracts and compounds.

Owing to compact scar tissue, it is necessary for the combination of natural products or crude extracts with some adjuvant as new dosage forms to increase their solubility, content, release time, uptake, and penetrability. These dosage forms include microemulsion [67], liposomes [66], solid lipid nanoparticle [68], and electrospun fibrous scaffolds [29]. Improvement of drug permeation may be a promising treatment in future research on the basis of the known medicinal plants.

In addition, some of these plant extracts or purified chemical components are prepared as traditional medicinal injections for the deep antiscar treatment. For example, Carthamus tinctorius injection, whose primary component is hydroxysaflor yellow A, softens hypertrophic scar tissue and inhibits fibroblast proliferation by decreasing the type I/type III collagens ratio and the TGF- $\beta_{1}$ level after local treatment [77]. The radix astragali injection also inhibits the proliferation and reduces scar thickness and hardness by reducing Smad3 and TGF- $\beta_{1}$ levels [78].

\section{Current Treatment and Prospects for Future Therapies}

Currently, occlusive dressings, compression therapy, intralesional steroid, cryosurgery, laser, radiation, surgical excision, and interferon therapy are curative for the majority of patients with hypertrophic scars [79]. Surgical therapy and excising fiber fraction are the common approaches for the treatment of hypertrophic scars. However, significant disadvantages were reported, such as the recurrence of adhesion after surgery as high as $45 \%-100 \%$ [54], which seriously limits its extensive application to scar prevention. Accordingly, physiotherapy is established, including occlusive dressings, pressure therapy, cryosurgery, radiation therapy, and laser therapy. Meanwhile, pharmacotherapy is also frequently applied, such as intralesional corticosteroid injection and topical drug treatment with interferon, bleomycin, 5-fluorouracil, verapamil, vitamin $\mathrm{E}$, imiquimod, TGF- $\beta_{3}$, or interleukin$10[79,80]$. Pharmacotherapy mainly inhibits inflammation, proliferation, and remodeling phase [7] or modifies ECM metabolism via interfering the pivotal molecules of MAPK, TGF- $\beta$, and PI3K signaling transduction.

However, there is no ideal treatment for hypertrophic scars so far and some chemical drugs also cause maleffects simultaneously. Many kinds of natural products from medicinal plants have good antiscar activity and show notable advantages due to their fewer side-effects. Therefore, in addition to widespread uses of surgical therapy, physiotherapy, and pharmacotherapy, there is a great need for developing new natural drugs more efficient than or synergizing with the existing ones. Many kinds of purified natural products originated from medicinal plants are abundant in the natural environment, such as Ginsenoside Rg3 [29], Oleanolic Acid [54], Resveratrol [42], Asiaticoside [34], and Genistein [13], and are popular as antiscar agents due to their easy obtainment and fewer side-effects. Hence, we overviewed the major current herbs and their preparations applied to the treatment of hypertrophic scars.

It is a challenge to identify and evaluate a safe, wholesome, and effective natural product against scars. Even though a number of new products have been reported by pharmacological tests in the last decades, many others remain unknown or untested. 


\section{Discussion}

In this review, we gathered publications on medicinal plants with antihypertrophic scar activity and addressed the question whether the treatment of scars with medicinal plants is effective in humans. Although in vivo and in vitro investigations play an important role in the evaluation of safety and effectiveness of medicinal plants in preclinical trials, there is no perfect denouncement for their ultimate success as human drugs. Clearly, animal data are not sufficient for the confirmation of the safety and efficacy of medicinal plants in humans owing to their physiological structure differences. Furthermore, there are some conflicting clinical trials reported. For example, it has been reported that honey was effective in rapidly cleaning infection and promoting wound healing, indicating that honey possessed anti-infection activity [81]. However, it was also reported that honey did not affect the wound, scar, length, and remained length [82]. Therefore, the effectiveness of some drugs needs to be further clarified.

On the other hand, only four publications reported negative results in our retried papers. Genistein phosphorylated cRaf, MEK1/2, ERK1/2, and p38 proteins, but not JNK protein [14]. Asiaticoside had no effect on the expression of Smad2, Smad3, and Smad4 [34], while madecassoside regulated keloid-derived fibroblasts proliferation, migration, F-actin filaments, cytoskeletal protein actin, and the phosphorylation of cofilin via p38 MAPK and PI3K/AKT signaling, but not ERK1/2 and caspase- 8 signaling [12]. Quercetin promoted phosphorylation of JNK and ERK, but not p38; it increased the protein and mRNA expression of MMP-1, but not type I collagen and TIMP-1 [38]. These studies indicate that the antiscar activity of medicinal plants needs to be scrutinized further.

Many traditional medicines used in folk medicine are reported to have antiscar activity, but only a few have been studied systematically in vitro or/and in vivo, such as rhubarb [60] and tamarind [63]. Although numerous in vitro studies have substantiated the antiscar activity of plant extracts and phytochemicals, there is very little evidence in humans. The number of clinical trials and their highlighted results are limited. The numerous traditional formulations effectively and extensively used in clinics have not been investigated. Also, the majority of the plants (Tables 1, 2, and 3) traditionally used as antiscar agents have not been investigated in animals. The phytochemicals with in vitro antiscar activity may have no effects in vivo due to the exceedingly high doses. Moreover, many of these phytochemicals have not been tested for their cytotoxicity, acute toxicity, or/and long-term toxicity in normal cells and animals, which seriously limits in vivo investigations. Only two medicinal plants have been reported on their untoward reactions and cytotoxic effects. The clinical efficacy and safety should be investigated simultaneously for medicinal plant extracts and compounds.

The natural barrier of skin can block drug getting through stratum corneum or decrease the amount of drug permeation, causing inefficiency or low-efficiency of drugs. Some adjuvants can significantly improve the penetrability of drugs and the desired therapeutic effects can be achieved. For example, hydroxycamptothecin (HCPT) is considered one of the most effective agents against scars, which prevents fibroblast proliferation and reduces epidural adhesion, but the poor solubility and short half-life severely limits its clinical application [65]. Some new dosage forms evidently reverse these conditions, such as microemulsion [67], liposomes [66], solid lipid nanoparticle [68], and electrospun fibrous scaffolds [29]. Therefore, the development of new dose types is necessary in order to ameliorate drug effects.

Although enormous progress has been achieved over the last years, the impact of medicinal plants on individual types of scars needs to be explored in more detail. Polymechanistic phytochemicals such as Genistein may have an advantage over targeted therapeutics, which simultaneously tackle scar treatment from multiple angles. Genistein can act on many target points, including suppression of PDGF-promoted TPK activation, decrease of types I/III precollagen and PCNA expression, reduction of c-Raf, MEK1/2, ERK1/2, and p38 protein phosphorylation, and inhibition of RTK-Ras-MAPK (ERK/p38) [13]. Further insights into the molecular mechanisms of phytochemicals will facilitate the development of new drugs for the prevention and treatment of human scars.

\section{Conclusion}

In conclusion, the scaring process is complicated. The characteristics of an appropriate therapy for the prevention and treatment of scars should comprise the following: simple and easy delivery, comparability (effectiveness) with current therapies, and minimal drug interaction with concomitant treatments and lack of significant side effects [83]. Manyextracts and compounds from medicinal plants can inhibit scarring. The main mechanisms are suppression of proliferation and/or induction of apoptosis in scar fibroblasts by regulation of several pathways, such as MAPK, PI3K/AKT, RhoA/ROCK-I, VEGF, FAK, and TGF- $\beta /$ Smad. Although the approaches described here are quite different and mechanisms are complicated, the utility should be maximized for medicinal plants as antihypertrophic scar agents. However, screening is necessary to minimize any potentially harmful side effects on human skin and health.

\section{Abbreviations}

AKT: Protein kinase B

ECM: Extracellular matrix

ERK: Extracellular regulated protein kinases

FAK: Focal adhesion kinas

HS: Hypertrophic scar

HKF: Human keloids fibroblast

HF: Human fibroblast

HPS: Human pathological scar

HSkF: Human skin fibroblast

HSRE: Hypertrophic scar model of the rabbit ears

LDH: Lactic dehydrogenase

MAPK: Mitogen-activated protein kinase

MMP: Matrix metalloproteinases

NF- $\kappa$ B: Nuclear factor-kappaB

PCNA: Proliferating cell nuclear antigen

PI3K: Phosphatidylinositol 3-kinase 
PS: $\quad$ Pathological scar

RESF: Rats epidural scar fibroblasts

ROS: $\quad$ Reactive oxygen species

SOD: Superoxide dismutase

SSSF: $\quad$ Systemic scleroderma skin fibroblast

TIMP-1: Tissue inhibitor matrix metalloproteinase-1

TGF- $\beta_{1}$ : Transforming growth factor- $\beta_{1}$

TPK: $\quad$ Tyrosine protein kinases

TxA2: Thromboxane A2.

\section{Conflict of Interests}

The authors declare that there is no conflict of interests.

\section{Authors' Contribution}

Qi Ye and Su-Juan Wang contributed equally to this work.

\section{Acknowledgments}

This work was supported by the National Natural Science Foundation of China (no. 81173462) and the Open Research Fund of State Key Laboratory Breeding Base of Systematic Research, Development and Utilization of Chinese Medicine Resources (no. 2014008).

\section{References}

[1] L. Yang, T. M. Witten, and R. M. Pidaparti, "A biomechanical model of wound contraction and scar formation," Journal of Theoretical Biology, vol. 332, pp. 228-248, 2013.

[2] P. Muangman, P. Aramwit, S. Palapinyo, S. Opasanon, and A. Chuangsuwanich, "Efficacy of the combination of herbal extracts and a silicone derivative in the treatment of hypertrophic scar formation after burn injury," African Journal of Pharmacy and Pharmacology, vol. 5, no. 3, pp. 442-446, 2011.

[3] D. Scott, "Poisons: poisoning-Harrison's story," in World Report on Child Injury Prevention, chapter 6, WHO, 2008.

[4] J. O. Adebayo and A. U. Krettli, "Potential antimalarials from Nigerian plants: a review," Journal of Ethnopharmacology, vol. 133, no. 2, pp. 289-302, 2011.

[5] Y. Sun, L. Wang, S. Sun, B. Liu, N. Wu, and X. Cao, "The effect of 10-hydroxycamptothecine in preventing fibroblast proliferation and epidural scar adhesion after laminectomy in rats," European Journal of Pharmacology, vol. 593, no. 1-3, pp. 44-48, 2008.

[6] P. T. Deshmukh, J. Fernandes, A. Atul, and E. Toppo, "Wound healing activity of Calotropis gigantea root bark in rats," Journal of Ethnopharmacology, vol. 125, no. 1, pp. 178-181, 2009.

[7] M. V. K. Patil, A. D. Kandhare, and S. D. Bhise, "Pharmacological evaluation of ethanolic extract of Daucus carota Linn root formulated cream on wound healing using excision and incision wound model," Asian Pacific Journal of Tropical Biomedicine, vol. 2, no. 2, pp. S646-S655, 2012.

[8] M. Jha, V. Sharma, and N. Ganesh, "Antioxidant and wound healing potential of Pistia stratiotes L.", Asian Pacific Journal of Tropical Disease, vol. 2, no. 2, pp. S579-S584, 2012.

[9] W. Yang, "Effect of Gelidiumamansii extractive on human hypertrophic scars fibroblasts," Modern Hospital, vol. 11, no. 5, pp. 11-13, 2011.
[10] P. S. Negi, "Plant extracts for the control of bacterial growth: efficacy, stability and safety issues for food application," International Journal of Food Microbiology, vol. 156, no. 1, pp. 7-17, 2012.

[11] J. Song, Y. Dai, D. Bian et al., "Madecassoside induces apoptosis of keloid fibroblasts via a mitochondrial-dependent pathway," Drug Development Research, vol. 72, no. 4, pp. 315-322, 2011.

[12] J. Song, H. Xu, Q. Lu et al., "Madecassoside suppresses migration of fibroblasts from keloids: involvement of p38 kinase and PI3K signaling pathways," Burns, vol. 38, no. 5, pp. 677-684, 2012.

[13] C. Cao, S. R. Li, X. Dai et al., "Genistein inhibits proliferation and functions of hypertrophic scar fibroblasts," Burns, vol. 35, no. 1, pp. 89-97, 2009.

[14] C. Cao, S. R. Li, H. Yao et al., "Effects of genistein on PCNA expression and cell cycle in human hypertrophic scar fibroblasts in vitro," Chinese Journal of Medicine Aesthetic Cosmetology, vol. 14, no. 1, pp. 159-162, 2008.

[15] C. Cao, S. R. Li, Y. Q. Chen et al., "The effects of Genistein on the proliferation and collagen synthesis of hypertrophic scar fibroblasts in vitro," Chinese Journal of Aesthetic Plastical Surgery, vol. 3, no. 2, pp. 220-222, 2007.

[16] C. Cao, S. R. Li, X. Qin et al., "Genistein inhibits transdifferentiation of human hypertrophic scar fibroblasts in vitro," Acta Academiae Medicinae Militaris Tertiae, vol. 7, no. 1, p. 30, 2008.

[17] M. Jurzak and K. Adamczyk, "Influence of genistein on c-jun, cfos and fos-b of ap-1 subunits expression in skin keratinocytes, fibroblasts and keloid fibroblasts cultured in vitro," Acta Poloniae Pharmaceutica, vol. 70, no. 2, pp. 205-213, 2013.

[18] X. Chen, L.-H. Peng, N. Li et al., "The healing and anti-scar effects of astragaloside IV on the wound repair in vitro and in vivo," Journal of Ethnopharmacology, vol. 139, no. 3, pp. 721-727, 2012.

[19] Z. Lin, S. Zhong, D. Liu, Y. Mao, and P. Ning, "Effect of tetrandrine on the TGF- $\beta$-induced smad signal transduction pathway in human hypertrophic scar fibroblasts in vitro," Burns, vol. 38, no. 3, pp. 404-413, 2012.

[20] Z. J. Yuan, X. S. He, and W. J. He, "Effects of Tetrandrine on proliferation and cycle of human hypertrophic scar-derived fibroblasts," Chinese Journal of Biochemistry and Pharmaceutics, vol. 29, no. 1, p. 127, 2008.

[21] W. T. Li, X. Y. Liu, and D. L. Liu, "Effects of tetrandrine on the expression of MMP-1 mRNA of fibroblasts derived from hypertrophic scar," Chinese Journal of Practice Aesthetic Plastic Surgery, vol. 3, no. 1, p. 29, 2005.

[22] Z.-D. Cao, C.-R. Shi, C.-B. Huang et al., "The effects of tetrandrine on activity of collagenase derived from human hypertrophic scar," Chinese Journal of Plastic Surgery, vol. 22, no. 6, pp. 448-450, 2006.

[23] P.-H. Zhang, S.-J. Luo, J. Liang et al., "Dosage-dependent effect of aloe-emodin on the fibroblasts apoptosi of hyperplastic scar," Chinese Journal of Clinical Rehabilitation, vol. 9, no. 30, pp. 152154, 2005.

[24] X. Z. Huan, L. W. Ji, and L. Hong, "Effects of Pterissemipinnata $5 \mathrm{~F}$ on Caspase- 3 and proenzyme activation in systemic scleroderma skin," Chinese Medicine, vol. 4, no. 6, pp. 629-631, 2009.

[25] Y.-S. Zhang, J.-H. He, S.-J. Luo, Y.-Y. Li, and M. Liang, "Effects of 5F from Pteris semipinnate L on growth of human pathological scars in nude mice," Journal of Southern Medical University, vol. 27, no. 11, pp. 1677-1680, 2007. 
[26] P. Chen, Z. Y. Wu, S. J. Luo, S. M. Tang, and L. M. Jiang, "Effects of Pteris Semipinnata 5F on the hypertrophic scar on rabbit ears," Journal of Guangdong Medical College, vol. 24, no. 1, pp. 112-113, 2006.

[27] D.-L. Fan, W.-J. Zhao, Y.-X. Wang, S.-Y. Han, and S. Guo, "Oxymatrine inhibits collagen synthesis in keloid fibroblasts via inhibition of transforming growth factor- $\beta 1 /$ Smad signaling pathway," International Journal of Dermatology, vol. 51, no. 4, pp. 463-472, 2012.

[28] W. J. Qun and N. X. Jiu, "Effect of oxymatrine on cell proliferation, apoptosis, cell cycle and erk1 expression of the fibroblasts derived from hypertrophic scar and keloids," Chinese Journal of Minimally Invasive Surgery, vol. 11, no. 2, pp. 259-263, 2011.

[29] W. Cui, L. Cheng, C. Hu, H. Li, Y. Zhang, and J. Chang, "Electrospun poly(L-Lactide) fiber with ginsenoside Rg3 for inhibiting scar hyperplasia of skin," PLoS ONE, vol. 8, no. 7, Article ID e68771, 2013.

[30] Z. R. Zhao, H. S. Liu, D. Zhang, P. Y. Li, and L. J. Lu, "Inhibitory effect of ginsenoside $\mathrm{Rg} 3$ on hypertrophic scars of rabbit ears," Journal of Jilin University (Medicine Edition), vol. 4, no. 1, p. 036, 2008.

[31] X. H. Hou, B. Cao, H. Q. Liu, Y. Z. Wang, S. F. Bai, and H. Chen, "Effects of osthole on apoptosis and TGF- $\beta 1$ of hypertrophic scar fibroblasts," Journal of Asian Natural Products Research, vol. 11, no. 7, pp. 663-669, 2009.

[32] K. Liu, X. F. Zhang, J. Zhang, Y. H. Qin, and Z. Lin, "Effect of angelicanaphtha on proliferation, apoptosis, collagen synthesis of human hypertrophic scar fibroblas," Chinese Journal of Aesthetic Medicine, vol. 21, pp. 1536-1538, 2012.

[33] J. H. Lee, H. L. Kim, M. H. Lee et al., "Asiaticoside enhances normal human skin cell migration, attachment and growth in vitro wound healing model," Phytomedicine, vol. 19, no. 13, pp. 1223-1227, 2012.

[34] B. Tang, B. Zhu, Y. Liang et al., "Asiaticoside suppresses collagen expression and TGF- $\beta /$ Smad signaling through inducing Smad7 and inhibiting TGF- $\beta$ RI and TGF- $\beta$ RII in keloid fibroblasts," Archives of Dermatological Research, vol. 303, no. 8, pp. 563-572, 2011.

[35] W. L. Zhao, R. X. Kuang, S. Liu, and L. Chen, "Effects of asiaticoside on the expression of TGF- $\beta 1$ mRNA in hypertrophic scar model of the rabbit ears," Chinese Journal of Aesthetic Medicine, vol. 1, no. 1, p. 36, 2009.

[36] L.-B. Dai, S. Pan, Y. Shen et al., "Effects of asiaticoside on dermal fibroblasts in hypertrophic scar," Chinese Pharmaceutical Journal, vol. 45, no. 14, pp. 1067-1072, 2010.

[37] C. M. Chun, "Research of effects on scars fibroblasts proliferation and collagen synthesis by Chinese herbs asiaticoside and matrine," Chinese Journal of Dermatovenereol Integrative Traditional and West Medicine, vol. 5, no. 5, pp. 11-15, 2006.

[38] J. W. Cho, S. Y. Cho, S. R. Lee, and K. S. Lee, "Onion extract and quercetin induce matrix metalloproteinase-1 in vitro and in vivo," International Journal of Molecular Medicine, vol. 25, no. 3 , pp. 347-352, 2010.

[39] J. Y. Liu, S. R. Li, and H. Yao, "Effects of Emodin on the proliferation and cell cycle of the cultured human hypertrophic scar fibroblasts in vitro," Chinese Journal of Aesthetic Plastic Surgery, vol. 5, no. 3, p. 17, 2007.

[40] S. Xia, S. R. Li, J. Y. Liu, C. Cao, H. Yao, and Z. Feng, "Effect of emodin on proliferation and intracellular free calcium of hypertrophic scar fibroblasts in vitro," Acta Academiae Medicinae Militaris Tertiae, vol. 20, no. 1, p. 24, 2007.
[41] S. Xia, S. R. Li, J. Y. Liu, C. Cao, H. Yao, and Y. Q. Chen, "Experiment study of emodin inhibting collagen anabolism and restraining cell cycle of hypertrophic scar fibroblasts," Chongqing Medicine, vol. 21, no. 3, pp. 2187-2188, 2007.

[42] Q. Zhu, H. S. Xia, and X. Zhang, "Effect of resveratrol on human scar fibroblasts and scar-derived fibroblasts of rabbit ears," Chinese Journal of Natural Medicne, vol. 1, no. 1, p. 2, 2006.

[43] X. X. Na and Z. Pehua, "Effect of Tan IIA on proliferation and apoptosis of fibroblasts in hyperplastic scar," Journal of Guangdong Medical College, vol. 23, no. 2, pp. 359-360, 2005.

[44] H. Liu, H. L. Yang, and C. Y. Meng, "Effect of STs in celL ultrastructure and free radical balance of hypertrophic scar fibroblast in vitro," Chinese Journal of Aesthetic Medicine, vol. 21, no. 11, pp. 2197-2200, 2012.

[45] S. F. Liu, H. Liu, and Y. H. Chi, "Effect of Sodium Tanshinone IIA Sulfonate on MMP-1mRNA expression for hypertrophic scars of rabbit ears," Journal of Mod Stomatology, vol. 4, no. 5, p. 16, 2011.

[46] J. Kang, H. Huang, and F. Zhu, "Effect of curcumin on growth and function of fibroblast in human hyperplastic scar," Chinese Journal of Integrated Traditional and Western Medicine, vol. 29, no. 5, pp. 1100-1113, 2009.

[47] D. C. Feng, G. Z. He, C. Jiang, W. Zhang, and C. B. Huang, "Effects of dihydroartemisinin on the hypertrophic scar in rabbits ears," Chinese Journal of Aesthetic Medicine, vol. 3, no. 2, p. 24, 2008.

[48] H. Kong, Q. Yu, and L. Zhu, "Experimental study on artesunate inducing apoptosis of hypertrophic scar fibroblasts," Chinese Journal of Reparative Reconstructive Surgery, vol. 21, no. 9, pp. 970-974, 2007.

[49] W. Li, R. Shi, C. B. Huang, and Y. Wu, "Inhibiting effect of artesunate on mastocyte in rabbit ear hypertrophic scar," Chinese Journal of Aesthetic Medicine, vol. 1, no. 2, p. 33, 2009.

[50] X. L. Nong, H. Chen, and S. H. Chen, "Growth inhibition of fibroblasts derived from human by arteannuin and artesunate in vitro," Journal of Guangxi Medical University, vol. 15, no. 2, p. $12,2009$.

[51] X. L. Nong, H. Chen, S. H. Chen et al., "Artemisinin and artesunate cream in the prevention and treatment of hypertrophic scar in rabbit ears," Chinese Journal of Dermatology, vol. 42, no. 2, pp. 421-424, 2009.

[52] H. Yao, S. R. Li, and J. Y. Liu, "Effects of PNS on the cell circle and TGF- $\beta 1$ of flbroblasts derived from human hypertrophic scar," Chinese Journal of Practice Aesthetic Plastic Surgery, vol. 4, no. 1, p. 28, 2005.

[53] H. Yao, S.-R. Li, J.-Y. Liu, Z. Li, and J. Wu, "Effects of Panax notogin seng on transdifferentiation of fibroblasts in human hypertrophic scar in vitro," Chinese Journal of Burns, vol. 23, no. 3, pp. 188-190, 2007.

[54] H. Zhang, Y. Zhang, Y.-P. Jiang et al., "Curative effects of oleanolic acid on formed hypertrophic scars in the rabbit ear model," Evidence-Based Complementary and Alternative Medicine, vol. 2012, Article ID 837581, 10 pages, 2012.

[55] K. T. Li, D. E. Liu, S. T. Li, H. Q. Lu, X. T. Chen, and X. X. Gao, "Effect of hirudin on matrix metalloproteinases of human hypertrophic scar fibroblast," Chinese Journal of Aesthetic Medicine, vol. 7, no. 2, article 031, 2012.

[56] X. J. Liu, M. J. Xu, S. T. Fan et al., "Xiamenmycin attenuates hypertrophic scars by suppressing local inflammation and the effects of mechanical stress," Journal of Investigative Dermatology, vol. 133, no. 5, pp. 1351-1360, 2013. 
[57] J. Y. Han, L. J. Hao, and J. H. Pang, "The effect of Carthamus tinctorius on proliferation and collagen synthesis of hypertrophic scar fibroblasts," Journal of Harbin Medical University, vol. 22, no. 4, p. 013, 2005.

[58] E. Jaszewska, M. Soin, A. Filipek, and M. Naruszewicz, "UVAinduced ROS generation inhibition by Oenothera paradoxa defatted seeds extract and subsequent cell death in human dermal fibroblasts," Journal of Photochemisty and Photobiology B: Biology, vol. 126, pp. 42-46, 2013.

[59] G.-Y. Yang, C.-L. Zhang, X.-C. Liu, G. Qian, and D.-Q. Deng, "Effects of cigarette smoke extracts on the growth and senescence of skin fibroblasts in vitro," International Journal of Biological Sciences, vol. 9, no. 6, pp. 613-623, 2013.

[60] Q. Wang, N. N. Zhang, H. Y. Li, M. Jiang, J. Gao, and G. Ba, "Active ingredients in rhubarb with anti-proliferative effects on scar fibroblasts," Yao Xue Xue Bao, vol. 47, no. 18, pp. 1618-1622, 2012.

[61] Y. S. Baek, Y. B. Ryu, M. J. Curtis-Long et al., "Tyrosinase inhibitory effects of 1,3-diphenylpropanes from Broussonetia kazinoki," Bioorganic and Medicinal Chemistry, vol. 17, no. 1, pp. 35-41, 2009.

[62] C. Feng, X. Wei, and H. Qeng, "The effective of scutellariabaicalensisgeorgi to TGF $\beta$ I, ColIIIexpression in scar of skin," Progress Journal of Clinic Medicine, vol. 28, no. 4, pp. 32-33, 2007.

[63] R. M. Havinga, A. Hartl, J. Putscher, S. Prehsler, C. Buchmann, and C. R. Vogl, "Tamarindus indica L. (Fabaceae): patterns of use in traditional African medicine," Journal of Ethnopharmacology, vol. 127, no. 3, pp. 573-588, 2010.

[64] W.-S. Kim, J.-S. Lee, G.-Y. Bae et al., "Extract of Aneilema keisak inhibits transforming growth factor- $\beta$-dependent signalling by inducing Smad2 downregulation in keloid fibroblasts," Experimental Dermatology, vol. 22, no. 1, pp. 69-71, 2013.

[65] J. Yang, B. Ni, J. Liu, L. Zhu, and W. Zhou, "Application of liposome-encapsulated hydroxycamptothecin in the prevention of epidural scar formation in New Zealand white rabbits," Spine Journal, vol. 11, no. 3, pp. 218-223, 2011.

[66] L. Zhu, B. Ni, J. Liu, J. Yang, Q. Guo, and W. Zhou, "Hydroxycamptothecin liposomes inhibit collagen secretion and induce fibroblast apoptosis in a postlaminectomy rabbit model," European Journal of Orthopaedic Surgery \& Traumatology, vol. 23, no. 1, supplement, pp. S85-S91, 2013.

[67] F.-H. Cao, W.-Q. OuYang, Y.-P. Wang, P.-F. Yue, and S.-P. Li, "A combination of a microemulsion and a phospholipid complex for topical delivery of oxymatrine," Archives of Pharmacal Research, vol. 34, no. 4, pp. 551-562, 2011.

[68] X. Chen, L.-H. Peng, Y.-H. Shan et al., "Astragaloside IV-loaded nanoparticle-enriched hydrogel induces wound healing and anti-scar activity through topical delivery," International Journal of Pharmaceutics, vol. 447, no. 1-2, pp. 171-181, 2013.

[69] V. Paocharoen, "The efficacy and side effects of oral Centella asiatica extract for wound healing promotion in diabetic wound patients," Journal of the Medical Association of Thailand, vol. 93, no. 7, pp. S166-S170, 2010.

[70] B.-Q. Song, S.-Z. Guo, Y. Han, W. Zhang, and K.-H. Lu, "Inhibition of VEGF expression by RNA inference (RNAi) technique as a possible new strategy for prevention of human hypertrophic scar," Bioscience Hypotheses, vol. 1, no. 5, pp. 272274, 2008.

[71] T. T. Foley and H. P. Ehrlich, "Through gap junction communications, co-cultured mast cells and fibroblasts generate fibroblast activities allied with hypertrophic scarring," Plastic and Reconstructive Surgery, vol. 131, no. 5, pp. 1036-1044, 2013.
[72] E. Funayama, T. Chodon, A. Oyama, and T. Sugihara, "Keratinocytes promote proliferation and inhibit apoptosis of the underlying fibroblasts: an important role in the pathogenesis of keloid," Journal of Investigative Dermatology, vol. 121, no. 6, pp. 1326-1331, 2003.

[73] B. Hinz, "Formation and function of the myofibroblast during tissue repair," Journal of Investigative Dermatology, vol. 127, no. 3, pp. 526-537, 2007.

[74] A. L. Pistorio and H. P. Ehrlich, "Modulatory effects of connexin-43 expression on gap junction intercellular communications with mast cells and fibroblasts," Journal of Cellular Biochemistry, vol. 112, no. 5, pp. 1441-1449, 2011.

[75] X. Hu, H. Wang, J. Liu et al., “The role of ERK and JNK signaling in connective tissue growth factor induced extracellular matrix protein production and scar formation," Archives of Dermatological Research, vol. 305, no. 5, pp. 433-445, 2013.

[76] P. Silambujanaki, C. H. Bala Tejo Chandra, K. Anil Kumar, and V. Chitra, "Wound healing activity of Glycosmis arborea leaf extract in rats," Journal of Ethnopharmacology, vol. 134, no. 1, pp. 198-201, 2011.

[77] L. Yan, F. Y. Xian, and Q. Lin, "Effect of carthamus tinctorius on fibroblasts and collagen I, III in hypertrophic scar of rabbit's ears," Journal of Clinical Rehabilitative Tissue Engineering Research, vol. 13, no. 37, pp. 7296-7300, 2009.

[78] Z. Yan and Q. Lin, "Effects of radix astragali on expression of transforming growth factor $\beta \mathrm{I}$ and smad 3 signal pathway in hypertrophic scar of rabbit," Chinese Journal of Burns, vol. 26, no. 2, pp. 366-370, 2012.

[79] A. Burd and L. Huang, "Hypertrophic response and keloid diathesis: two very different forms of scar," Plastic and Reconstructive Surgery, vol. 116, no. 7, pp. 150e-157e, 2005.

[80] C. D. Humphrey and J. R. Thomas, "Improving scars with minimally invasive and topical treatment," Operative Techniques in Otolaryngology-Head and Neck Surgery, vol. 22, no. 1, pp. 94-100, 2011.

[81] A. A. Adewumi and A. A. Ogunjinmi, "The healing potential of honey and propolis lotion on septic wounds," Asian Pacific Journal of Tropical Biomedicine, vol. 1, supplement 1, pp. S55S57, 2011.

[82] T. Heidari, N. Roozbahani, L. Amiri Farahani et al., "Does Iranian Astragalus gossypinus honey assist in healing caesarean wounds and scars?" European Journal of Integrative Medicine, vol. 5, no. 3, pp. 226-233, 2013.

[83] A. Bayat, "Reduction of hypertrophic scar via retroviral delivery of a dominant negative TGF-beta receptor II," Journal of Plastic, Reconstructive and Aesthetic Surgery, vol. 60, no. 1, pp. 73-74, 2007. 


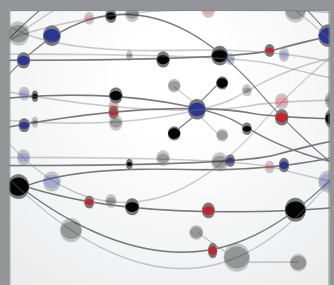

The Scientific World Journal
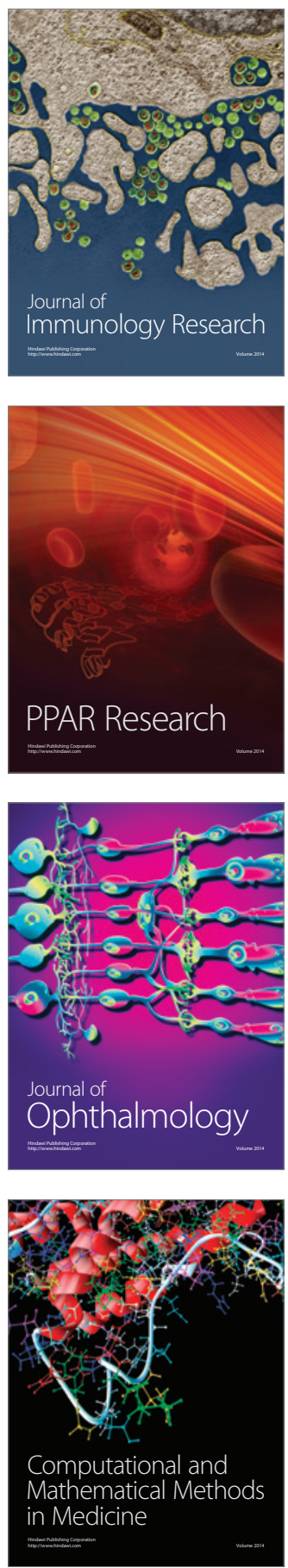

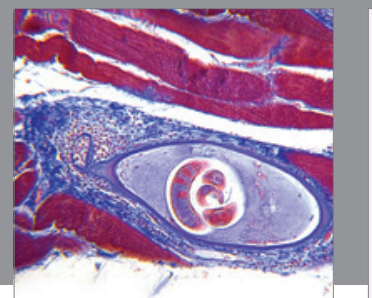

Gastroenterology

Research and Practice
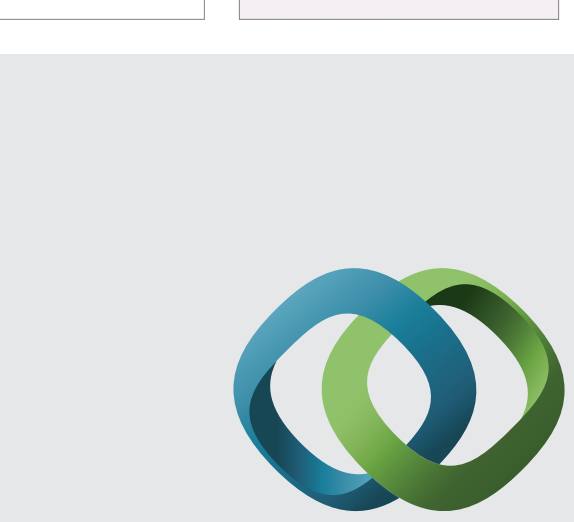

\section{Hindawi}

Submit your manuscripts at

http://www.hindawi.com
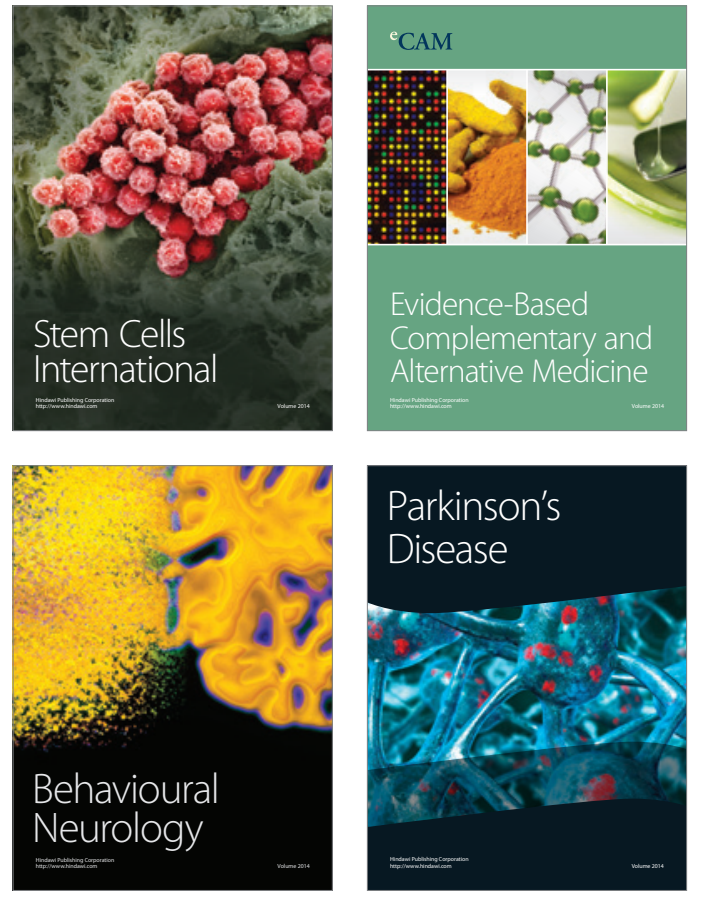
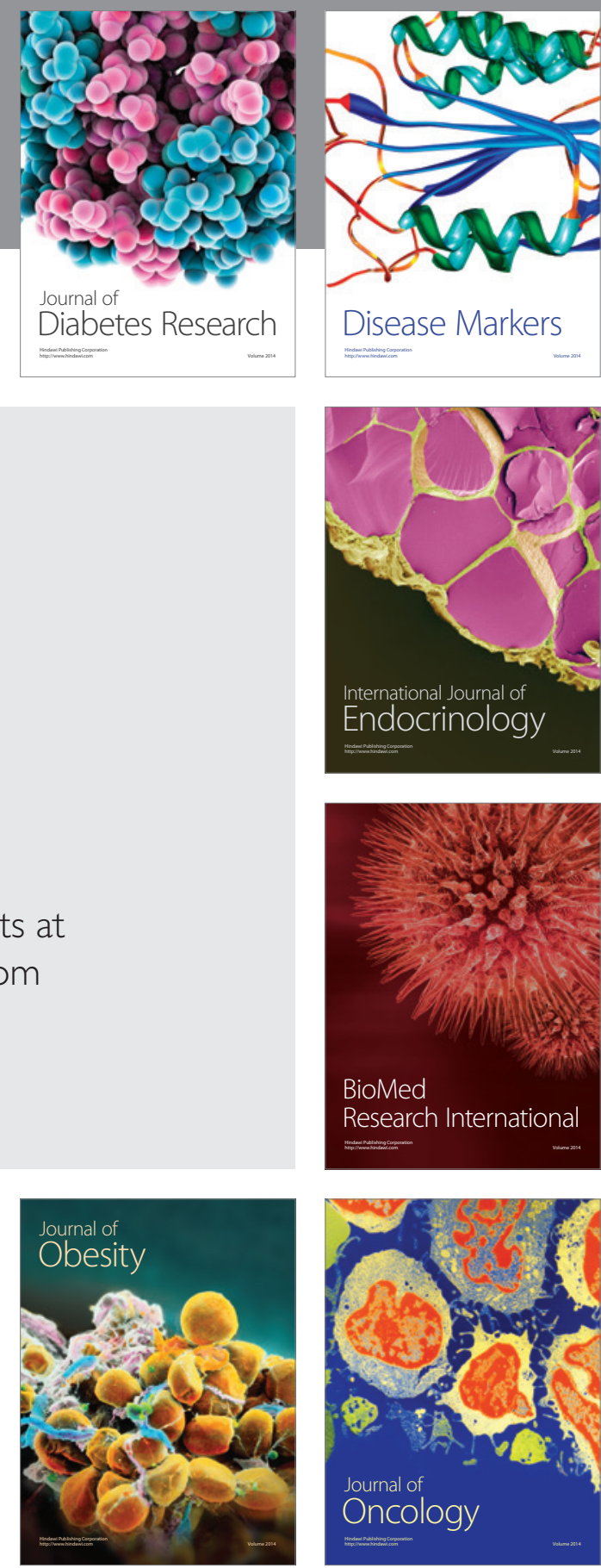

Disease Markers
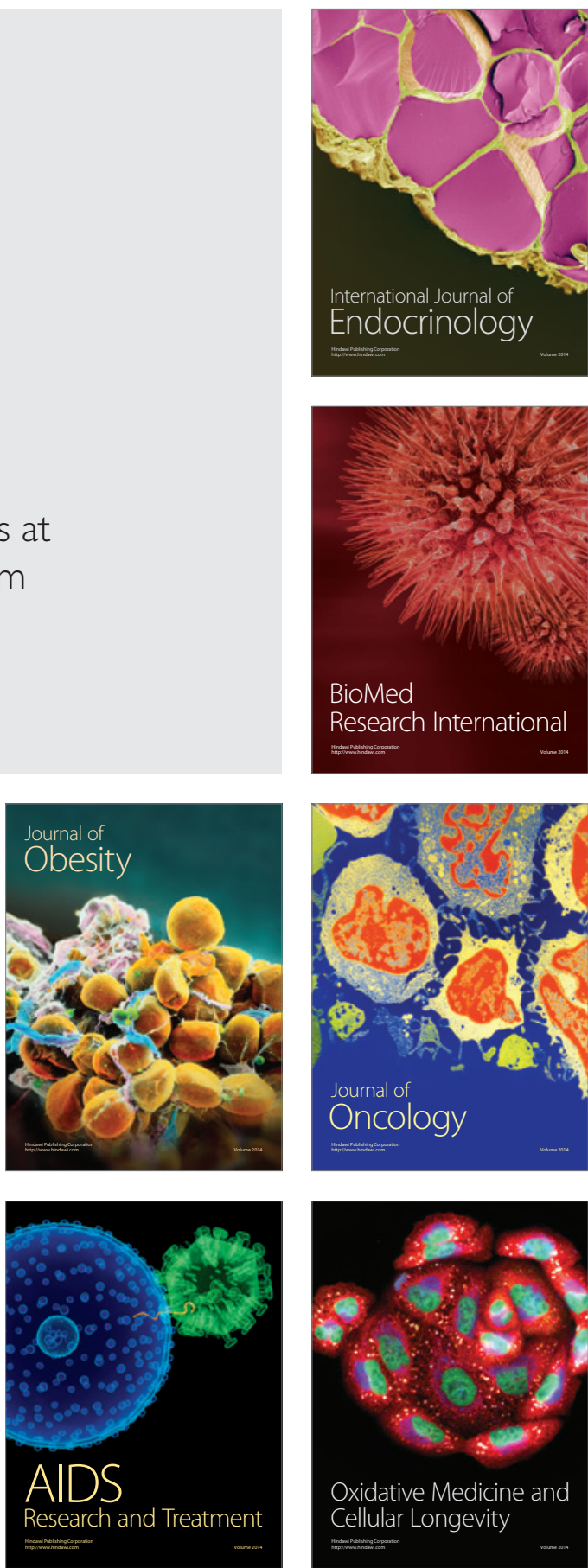